\title{
El Concepto de Utopía de Rafael Landívar en la Rusticatio Mexicana
}

En el año 1781 se publicó en Módena, Italia, la primera edición de la Rusticatio Mexicana, poema en versos latinos del jesuita guatemalteco Rafael Landívar, que constaba de diez libros o cantos, dedicados a la descripción de variados aspectos de la naturaleza y de la vida campestre de la Nueva España. Por la buena acogida que esta obra tuvo entre el público culto su autor se decidió a tirar una segunda edición, impresa en Bolonia, en 1782, corregida y aumentada con cinco nuevos cantos y un apéndice a modo de epílogo. ${ }^{2}$ Esta segunda edición, por su superioridad sobre la anterior, quedó como definitiva y como original para las sucesivas ediciones, y es la que tomo como fuente de interpretación y de referencias en mis comentarios.

Es mi propósito en este breve estudio dar una idea de las circunstancias que envolvieron a Landívar en relación con su obra, y del contenido general de ella, y examinar con el posible detenimiento el Libro VI, en el que se ocupa de la castores ( $f i b r i$ ), con la descripción de su industriosa vida colectiva, de la que trasciende una concepción político-social utópica. La Rusticatio, en su conjunto, sobrepasa con mucho el mero valor de un ingenioso ejercicio poético en hexámetros latinos. En un período en el que algunos, como Georges-Louis

\footnotetext{
${ }^{1}$ La referencia completa es Rusticatio Mexicana, seu rariora quaedam ex agris Mexicanis decerpta, atque in libros decem distributa a Raphaele Landivar (Mutinae, MDCCLXXXI). Apud Societatem Typographicam. Graciela P. Nemes, "Rafael Landivar and Poetic Echoes of the Enlightenment," en The Ibero-American Enlightenment, edited by A. Owen Aldridge (Urbana, Ill., 1971), p. 298, cita la descripción de esta edición en José Toribio Medina, Noticias biobibliográficas de los jesuitas expulsos de América en 1767 (Santiago de Chile, 1914), agregando que es "... an edition of 133 pages now merely known through a bibliographical notice." No obstante existen, al menos, un ejemplar en la John Carter Brown Library, Providence, Rhode Islan 1, y otro en el British Museum.

${ }^{2}$ Raphaelis Landivar Rusticatio Mexicana. Editio altera auctior, et emendatior (Bononiae, MDCCLXXXII). Ex Typographiae S. Thomas Aquinatis. Se hizo en Guatemala, en 1950, una edición facsímil, publicada por la Universidad de San Carlos, y precedida de una Introducción por José Mata Gavidia.
} 
Buffon, Guillaume Raynal, Cornelio DePauw y William Robertson alegaban la inferioridad no sólo de las razas indígenas, sino también la del terreno, clima, flora y fauna del Nuevo Mundo, la Rusticatio Mexicana aparece como una afirmación orgullosa de la belleza y riquezas naturales del campo americano, de la abundancia y calidad de sus productos agrícolas y ganaderos, y de la pericia industrial y capacidad intelectual de sus habitantes. El antagonismo que se fue creando entre españoles y criollos y el desprecio del europeo por el criollo pudieron también acaso influir a Landívar de un modo indirecto en el aludido carácter de su poema. Según Antonello Gerbi, “...el criollo, resentido, se exaltaba en el entusiasmo por su tierra. Su patriotismo nacía de ese modo, por legítima reacción, sobre presupuestos naturalistas, como apego al 'país,' al terruño, antes que a las tradiciones, como orgullo telúrico americano. ", Agrega Gerbi que "...el orgullo americano nacía como ponderación de los méritos físicos del terruño, $\mathrm{y}_{4}$ no como vanagloria de una herencia histórica o de una mítica antigüedad." Gerbi señala varias referencias, en autores de la colonia, a la profusión de oro y plata en América, fenómeno que se identifica con la bondad de la tierra, y que llega a ser motivo de jactancia. Estas ideas y sentimientos hacen muy significativo que Landívar dedique, no uno, sino dos libros de los quince de su poema a las minas de oro y plata y a su explotación.

Es interesante notar que el mismo año de 1781 en que apareció la Rusticatio Mexicana se imprimieran en Roma otros dos poemas latinos relacionados por su asunto con aspectos del tema de la Rusticatio, uno, De Rusticis Brasiliae rebus, del jesuita portugués José Rodrigues Melo, y el otro, De sacchari opificio, del también jesuita portugués Prudencio do Amaral. ${ }^{5}$ De Rusticis Brasiliae rebus trata de las riquezas del campo del Brasil, tales como la mandioca, el tabaco y el ganado. De sacchari opificio trata de la fabricación del azúcar. Al ocuparse, en sus escritos latinos, Landívar y otros jesuitas americanos exilados en Italia, como los padres Francisco Javier Alegre, Francisco Javier Clavijero, Diego José Abad y Agustín Pablo de Castro, de cosas peculiares de América, desconocidas para los antiguos romanos y para los humanistas del Renacimiento, se les planteó la necesidad de inventar adecuados neologismos latinos que las expresaran. Y buenos latinistas como eran todos ellos hay que reconocerles el mérito de haber salido airosos de la difícil prueba. Así, por ejemplo, "mandioca" se expresó en latín por radix brasilica ("raíz brasileña"), y "tabaco" por herba nicotiana ("yerba de nicotina"). (La palabra "nicotina" viene de Jacques Nicot, embajador francés en Lisboa, por cuyo medio se introdujo el tabaco en Francia

${ }^{3}$ La disputa del Nuevo Mundo. Historia de una polémica, 1750-1900. Trad. de Antonio Alatorre (México, 1960), p. 165.

${ }^{4}$ Ibid, p. 166.

${ }^{5}$ Josephi Rodrigues de Mello Lusitani Portuensis De Rusticis Brasiliae Rebus Carminum Libri IV. Accedit Prudentii Amarilii Brasiliensis De Sacchari Opificio Carmen (Romae, MDCCLXXXI). Ex Typographia Fratrum Puccinelliorum. Estos dos poemas han sido reeditados y traducidos al portugués: Geórgicas Brasileiras. Versão em linguagem de João Gualberto Ferreira dos Santos Reis. Biografias e notas de Regina Pirajá da Silva (Rio de Janeiro, 1941). 
en 1560.) Landívar se desempeñó bien con los numerosos problemas de neologismos que tuvo que resolver. Así, la "caña de azúcar" es en su poema nectarea canna, las "melazas" son nectareum mel, el "vaquero" es bubulcus, el que cuida los bueyes, según su etimología clásica, y la "silla del caballo" es phalerae, que antiguamente designaba un ornamento de metal que se ponia al pecho de los caballos.

Poco se sabe de la vida del padre Landívar, y lo que consta con certeza está reducido a fríos datos de estadística. Hay dos fuentes de información que porser únicas resultan indispensables. Una, los Estudios bio-bibliográficos sobre Rafael Landívar de José Antonio Villacorta," con datos necesarios para poder contestar a las cuestiones más importantes de la pregunta, "quién fue Landívar," y para recrear el fondo y ambiente de la sociedad guatemalteca en que vivió, salvo unos pocos años de formación religiosa y cultural en México, hasta su partida para Italia. La otra fuente, que pocos han conocido y utilizado, es una breve biografía, de sólolocho páginas, contenidas en un trabajo sobre miembros de la Compañía de Jesús en el exilio de Italia, del padre Félix de Sebastián, que nunca se imprimió, y que es lo más importante de que se dispone para poder contestar a la otra pregunta pendiente, "cómo fue el padre Landívar." Con estas dos fuentes y con datos sueltos de la época que se han recogido, se puede organizar una sintesis biográfica, cuyos rasgos generales son los siguientes.

Rafael Landívar y Caballero nació en Guatemala en 1731, de distinguida familia de la ciudad. Su padre, don Pedro Landívar, un capitán del ejército español, había llegado a Guatemala procedente de una población de Navarra, y era persona en extremo religiosa, dato muy importante por la influencia definitiva que esta religiosidad tuvo en la orientación y vida de su hijo Rafael. Muy pronto comenzó a cursar estudios regulares en el Colegio de San Francisco de Borja de la cuidad de Guatemala, regido por los jesuitas, que alternó con la asistencia a clases en la Real Universidad de San Carlos. En 1746 otuvo el grado de Bachiller en Filosofía, en el Colegio de San Francisco de Borja, y al año siguiente, después de brillantes exámenes, el de Maestro en Artes en la Universidad de San Carlos, y más adelante, mediante nuevos exámenes, el grado de Licenciado en Filosofía. Después de la muerte de su padre, en 1749, Landívar se decidió a llevar a cabo sus propósitos de hacerse sacerdote y de ingresar en la Compañia de Jesús, y con este objeto se trasladó a México. Allí pasó la probación de los dos años de noviciado, hizo sus primeros votos, y repasó y completó sus estudios, parte de ellos al menos, en el Colegio Máximo de San Pedro y San Pablo, acreditada institución docente de los jesuitas en la Ciudad de

\footnotetext{
${ }^{6}$ (Guatemala, 1931).

${ }^{7}$ De este trabajo existen dos ejemplares manuscritos. Uno, el más completo, de dos volúmenes, se conserva en la Biblioteca del Archiginnasio de Bolonia. Otro, de un volumen, se encuentra en el Archivo de la Provincia jesuita de México. El padre Manuel I. Pérez publicó la biografía de Landívar en "El padre Rafael Landívar, S.J.," Estudios Centroamericanos (San Salvador), 5 (mayo de 1950), pp. 24-32.
} 
México. La escasez de datos deja muchos blancos en las actividades de Landívar desde esta época hasta su salida para el destierro. Regresó a su región nativa, y en 1765 aparece como rector del Colegio de San Francisco de Borja, en el que años antes había sido estudiante. En 1767 fue desterrado con sus compañeros de Orden por el decreto de Carlos III que expulsó a los jesuitas de España y de sus colonias. Y comenzó así la etapa final de su vida, de incertidumbres y sufrimientos. Los jesuitas de Guatemala fueron concentrados en Omoa (Honduras), y partieron de alli para su destierro en Italia, con escalas en Habana, Cádiz y Cerdeña. La vida de los exilados en Italia estuvo bien surtida de privaciones, de falta de medios económicos y de contrariedades, la más penosa de todas ellas, sin duda, la disolución de la Orden por breve pontificio del Papa Clemente XIV, de 21 de julio de 1773. Landívar aparece durante estos años finales como profesor y director, en Bolonia, de un centro de enseñanza para los jóvenes jesuitas, que llevaba el nombre de Casa de Sapiencia. Murió en Bolonia en 1793. En las notas biográficas del padre Félix Sebastián se ve al padre Landívar como estudioso, inteligente, inclinado a la vida retirada, afectuoso, y de delicada sensibilidad en peligro de disturbios emocionales. El destierro y aislamiento en Italia lo hicieron más reconcentrado, más aficionado al estudio, más amigo de la soledad. Un bien le debe la cultura americana a esta situación, el poema Rusticatio Mexicana, que de haberse quedado Landívar en Guatemala haciendo su vida normal acaso nunca hubiera aparecido.

Rafael Landívar pertenece por su formación cultural en México y por su poema sobre el campo de este país al grupo de jesuitas mexicanos latinistas y humanistas de la segunda mitad del siglo XVIII, que incluye a personalidades como las de los padres Francisco Javier Clavijero, Diego José Abad, Agustín Pablo de Castro y José Rafael Campoy, quienes se distinguieron como profesores, historiadores, teólogos y literatos. Se formaron intelectualmente en un período de transición, en el que la enseñanza tradicional de la filosofía escolástica se veỉa confrontada por la filosofía moderna, y en parte forzada a ceder o ajustarse a las nuevas corrientes racionalistas y experimentales. La afición de estos autores a los clásicos greco-latinos tiene fácil explicación por una trilogía de motivos, la tradición humanista, reafirmada en el siglo XVIII por el neoclasicismo, la tradición docente de los jesuitas, y la categoria del latín como lengua oficial de la Iglesia Católica.

La expulsión de los jesuitas en 1767 de los dominios españoles permitió a los jesuitas hispanoamericanos, exilados en Italia, ponerse en contacto con los literatos e intelectuales españoles, franceses e italianos, y a través de ellos enterarse de las nuevas corrientes filosóficas y literarias europeas. El exilio tuvo otros resultados positivos. Por un lado, los jesuitas españoles Francisco Javier Lampillas y Juan Andrés, hondamente afectados por las alegaciones de algunos autores italianos, como Girolamo Tiraboschi y Saverio Bettinelli, que hacían responsables a la literatura barroca española del XVII de perniciosas influencias en la italiana contemporánea, defendieron vigorosamente la literatura y cultura 
españolas en obras que lograron merecida fama. Y para vindicar a América de las denigraciones de gente como Raynal, Buffon y De Pauw, el mexicano Clavijero escribió su interesante Historia antigua de México, ${ }^{8}$ considerada como la primera historia moderna sobre esa materia. Por otro lado, las corrientes culturales francesas llegaron así a España y América a través de Italia. Este grupo de escritores fue trilingüe, y todos ellos se valieron para la expresión y difusión de sus ideas, del latín, del español y del italiano, preferentemente de este último, por la sencilla razón de estar su público del momento principalmente formado por italianos. El castellano lo cultivaron menos, y el latín lo reservaban generalmente para tratados filosóficos y teológicos y para temas relacionados con la tradición humanista. En algunos casos aislados el latín era la solución para los que no dominaban lengua italiana. Aunque el cultivo del latín como lengua literaria ya estaba declinando en el siglo XVIII, todavía se consideraba importante como lengua de la cultura, especialmente entre los jesuitas, debido a su formación humanista. A propósito de la decadencia del latín, dice el padre Andrés, aludiendo a Voltaire y D'Alembert: "Son comunes los lamentos del abandono en que al presente se encuentra la lengua latina en boca de los escritores modernos: ...y á vista del desprecio en que se tiene el latinismo, parece que se debía considerar este siglo como el fatal destructor de aquel noble y elegante lenguage." No obstante, Andrés se apresura a agregar, en tono de esperanza optimista: "Pero yo, cotejando los escritos latinos del presente siglo con los antecedentes, pienso muy al contrario, y casi me prometo, que el nuestro será tenido de la posterioridad por la época mas feliz de la cultura de aquella lengua." Nosotros, con la ventaja de casi 200 años de perspectiva histórica, podemos concluir, en cuanto al cultivo del latín, que si no fue la más feliz la época del padre Andrés, sí fue la última de su brillante historia.

Miguel Batllori ha señalado diferencias en la actitud y trabajo intelectual y literario entre los jesuitas españoles y los hispanoamericanos, o "españoles americanos," como comúnmente se los llamaba. Los españoles daban preferencia a los estudios histórico-críticos y al enciclopedismo universal, mientras que los americanos, en parte por nostalgia, en parte por un incipiente nacionalismo, se limitaban a su ámbito histórico y geográfico. "Los americanos,-dice Batllori-por lo general, se mantienen al margen de la diatriba y de la apologética, para contentarse con reelaborar la historia y con describir morosamente las bellezas de sus tierras-como en la Rusticatio Mexicana de Landívar - tan desconocidas en Europa. Así brotan, en el destierro de Italia, tan abundante número de historiadores: Alegre, Clavijero y Cavo entre los mexicanos...."10

${ }^{8}$ Salió primero en italiano, bajo el título de Storia antica del Messico, 4 vols.(Cesena, 1780-1781).

${ }^{9}$ Origen, progresos y estado actual de toda la literatura (Madrid, 1784), II, pp. 393-394.

${ }^{10}$ La cultura hispano-italiana de los jesuitas expulsos. Españoles, hispanoamericanos, filipinos, 1767-1814 (Madrid, 1966), p. 577. 
La Rusticatio Mexicana, que es hoy considerada por muchos críticos como el poema descriptivo más importante de la literatura hispanoamericana del siglo XVIII, en latín y castellano, fue casi totalmente desconocida en Europa y América hasta 1924, cuando salieron dos traducciones castellanas, una en prosa, Rusticación Mexicana, de Ignacio Loureda, ${ }^{11}$ y otra en verso, Geórgicas Mexicanas, del padre Federico Escobedo.2 Desde entonces se han hecho dos traducciones más: la española de Octavio Valdés, Por los campos de México, ${ }^{13}$ que es la traducción más fiel de las españolas, y una en inglés, Mexican Country Scenes, hecha por Graydon Regenos. ${ }^{14}$

Se ha formulado varias veces la pregunta "¿por qué escribió Landívar la Rusticatio Mexicana en latín?"' Supone Luis Beltranena ${ }^{15}$ que Landívar escribió en latín para demostrar su resentimeinto contra el espíritu racionalista de aquel tiempo, anticristiano y dominado por los filósofos franceses, y que, en consecuencia, rechazó con esa reacción toda la literatura escrita por entonces en lenguas romances. Esta teoría carece en absoluto de base, entre otras razones porque, como indicaremos más adelante, Landívar participaba, en cuanto su fe religiosa se lo permitía, de este espíritu racionalista, que en ciertos aspectos deja traslucir en su poema. La verdadera explicación la apunta el padre Sebastián en su citada referencia biográfica, donde dice: "Por divertir algún tanto el ánimo, escribió en verso Latino, en que tenía mucha facilidad, una Obra, que dio a la Imprenta con el título de Rusticatio Mexicana, seu rariora quaedam ex agris Mexicanis decerpta, Obra que ha sido mui apreciada de los Eruditos de Italia, cuyos Analistas le han tributado las alabanzas de que es merecedor el dicho trabajo, único en su línea. Este estudio le ocupaba poco tiempo, pues lo tomaba por evagar el ánimo, llevándole siempre su atención, y su cuydado, el de la Sagrada Escriptura, Theología y Ascética." ${ }^{, 16}$ Hay que tener en cuenta además la larga tradición de los jesuitas, sobre todo en Italia, de usar el latín no sólo en la literatura didáctica sino también en otros géneros más poéticos. Entre muchos ejemplos de autores italianos que escribieron en latín sobre poesía didáctica en general y sobre la referente al campo en particular pueden mencionarse el Rusticus (1483) de Angiolo Poliziano, poeta y humanista, compuesto para ser recitado como introducción a sus conferencias sobre Hesíodo y Virgilio; De hortis Hesperidum (1505) de Giovanni Pontano, también humanista, sobre el cultivo de

\footnotetext{
${ }^{11}$ Rusticación Mexicana de Rafael Landivar. Trad. literal y directa de la segunda edic. de Bolonia, 1782 (México, 1924).

${ }^{12}$ Geórgicas Mexicanas. Versión métrica del poema latino del padre Rafael Landívar, S. J. (México, 1924).

${ }^{13}$ Primera edic. (México, 1942). Segunda edic., primera bilingüe (México, 1965).

${ }^{14}$ En Philological and Documentary Studies, vol. I. Middle American Research Institute. Tulane University (New Orleans, 1948), pp. 155-312.

15 “ ¿Por qué Landívar escribió en latín?," en Homenaje a los poetas nacionales, Rafael Landivar y Fray Matías de Córdoba, de la O. P. (Guatemala, 1932), pp. 89-105.

${ }^{16}$ Art. cit., p. 30.
} 
la naranja, el limón y la cidra; De bombycum cura et usu (1527), (Del cultivo y utilidad del gusano de seda), de Girolamo Vida; y el Syphilis, del médico veronés Girolamo Fracastoro, publicado en 1550. De esta obra escribió el célebre historiador inglés, Henry Hallam, "There is no reader but must admire the beauty and variety of his digressions."17

Los antecedentes más directos de la Rusticatio Mexicana, después de las Geórgicas de Virgilio, son el Hortorum libri IV (1665) de René Rapin, jesuita francés, que se considera el poema geórgico más importante del siglo XVII, y el Praedium Rusticum, del jesuita francés Jacques Vanière, de 1707. Las Geórgicas del "divino" Virgilio eran consideradas como el poema más perfecto de ese género, del tenido por mejor poeta de todos los tiempos. En opinión de Francisco Javier Alegre, gran latinista mexicano y compañero de Landívar, "...las Geórgicas...parecen dictadas por las Gracias mismas." 18 Un cotejo detenido revela que, aparte de haber en la Rusticatio muchos ejemplos de directa imitación lingüística de las Geórgicas de Virgilio, el poema guatemalteco es muy virgiliano en espíritu, como se refleja, por ejemplo, en el amor profundo a la patria, a la tierra, a la naturaleza, en los anhelos de amor fraterno y de paz y armonía social, en la admiración por el trabajo, y en el profundo sentido ético de la vida. ${ }^{18 b i s}$ No obstante, uno de los méritos que más se destacan en las Geórgicas

${ }^{17}$ Introduction to the Literature of Europe in the Fifteenth, Sixteenth, and Seventeenth Centuries (Paris, 1839), I, 340.

${ }^{18}$ En "Arte poética de Mr. Boileau," traducida a rima castellana. "Notas al Canto Primero," en Opúsculos inéditos, edic. de Joaquín García Icazbalceta (México, 1889), p. 35.

18 bis Se pueden citar como antecedentes della Rusticatio Mexicana los tres diálogos en latín de Francisco Cervantesjde Salazar,"Academia Mexicana," "Civitas Mexicus Interior" y "Mexicus Fxterior" (1554), y la Grandeza Mexicana (1604) de Bernardo de Balbuena, por sus descripciones del paisaje y de la vida de México y por su espíritu americano, aunque, por lo demás, el objetivo, el modo y el estilo de estos dos autores no coinciden con las características del poema de Landivar. Cervantes de Salazar escribe con viveza y entusiasmo de la Real Universidad de México, de la ciudad propiamente dicho y de sus alrededores, y enumera con orgullo una selección de productos naturales del campo mexicano, que suenan extraños en latín ("frisoles, aguacates, guaiauae mamei, capotes, camotes, gicamae, cacomitae, mizquites, tunae, gilotes, xocotes"), y que hacen recordar a landívar cuando, para mencionar cosas nuevas, desconocidas por los autores latinos y por los humanistas del Renacimiento, latiniza voces de origen nahuatl.

Balbuena describe con estilizado lenguaje renacentista la ciudad de México y los aspectos de su situación a fines del XVI, y enumera con elogio sus caballos, industrias, artes, letras, oficios, diversiones y comestibles, la flora de su paisaje, su gobierno y religión. Balbuena y Landívar coinciden en el propósito de representar una realidad objetiva. Balbuena previene al lector que solo dirá aquello de lo que es testigo, y Landívar le asegura lo mismo en el Monitum o Advertencia: "Quae vidi refero, quaeque mihi testes oculati, caeteroquin veracissimi, retulere." (Cuento lo que he visto, o lo que testigos oculares, y por otra parte sumamente veraces, me han referido.) Mientras que Balbuena, entusiasmado por la ciudad de México, que para él es la antítesis del "campo torpe y pueblo rudo," refleja el estilo elegante y refinado del poeta cortesano del Renacimiento, que escoge sus temas con esmero y solo pinta lo estéticamente bello y "poetizable," Landivar, gran admirador del campo, con su actitud de ilustrado dieciochesco lo representa todo, lo hermoso junto con lo feo, buscando una objetividad exacta, de indiferencia fotográfica. En el Capítulo VI de la Grandeza Mexicana, ("Primavera inmortal y sus indicios"), se puede apreciar al Balbuena paisajista. Según María del Carmen Millán, El paisaje en la poesía mexicana (México, 1952), pág. 52, "En la Grandeza mexicana, se encuentra en proporción muy grande la descripción, la información, el registro, pero logra en muchas ocasiones el paisaje. Este paisaje está sublimado por hipérbole y condicionado 
deVirgilio, su perfección formal, no logra las deseables proporciones en la obra de Landívar. En ésta, además, no cohesiona su contenido la ley de unidad que rige el modelo clásico. Landívar combina lo propiamente agrícola con cuanto digno de valor es capaz de captar sobre el campo mexicano, su geografía, su vegetación natural, su población animal, la riqueza del subsuelo, la elaboración industrial de productos vegetales y minerales, y hasta los juegos populares del país. Describe los lagos, los ríos, las cataratas, las aves, las fieras, el ganado doméstico, la fabricación del índigo, o añil, y del azúcar, la explotación de las minas de oro y plata, en resumen todo cuanto se puede apreciar como eficiente respuesta a los denigradores de las tierras de América; y ésta se podría decir que es la ley íntima de unidad de su poema.

A nuestro juicio el libro más interesante y curioso de la Rusticatio es el sexto, que trata de los castores, especie que todavía se encuentra, aunque en número limitado, en el norte de México, en los estados de Sonora, Juárez, Chihuahua, Cohahuila, Nuevo León y Tamaulipas. El castor tiene su adecuada y segura habitación, más que en regiones de la Nueva España, en zonas frías como las Canadá y norte de los Estados Unidos, donde aislados del hombre, cuya presencia les ha sido funesta, abundaban en pasados tiempos. No hay ninguna evidencia de que Landívar observara personalmente a los castores. En una nota que pone al verso 14, cita al naturalista francés Jacques Valmont de Bomare, quien, copiando a Buffon, escribe que en América se encuentran los castores por cima del grado 30 de latitud norte hasta el grado 60, y aún más arriba. Un cotejo del artículo de Valmont sobre el castor en su Dictionnaire raisonné universel d'histoire naturelle ${ }^{19}$ y del Libro VI de la Rusticatio revela que Landívar tomó casi todos sus datos de este naturalista, quien, a su vez, se basó directamente en la Histoire naturelle de Buffon, ${ }^{20}$ obra de grandísima difusión y popularidad en el siglo XVIII, y de capital importancia en el desarrollo de la ciencia moderna sobre la naturaleza. La impresión que nos dan Buffon y Valmont de Bomare de los castores es antropomórfica; estos animales, a semejanza de lo que debería pasar entre los hombres, sólo pueden funcionar como una comunidad basada en el amor, la paz y la cooperación altruísta. El hecho de que Landívar haya dedicado un libro entero de 360 versos a los castores, más representativos de Norteamérica que de México, es una prueba de que la Rusticatio es algo más que un mero

a un medio, a la ciudad, es decir, a una porción cultivada del paisaje mexicano." Para un estudio interesante sobre la representación del paisaje en Balbuena y Landívar, véase María del Carmen Millán, op. cit., "El paisaje hiperbólico (Bernardo de Balbuena)," cap. II, págs. 33:56, y "El paisaje objetivo (Rafael Landívar)," cap. IV, págs. 81-101.

${ }^{19}$ La primera edic. del Dictionnaire es de París, 1764, 5 vols. Se reeditó varias veces hasta 1800. Hemos utilizado la de 1791: "Castor," vol. XIII, pp. 459-467.

"Véase el artículo sobre "Le castor," Histoire naturelle, générale et particulière, avec la description du Cabinet du Roi (Paris, 1760), vol. VIII, pp. 282-332. El uso por Buffon de términos como "bourgades," "république," "tribus," "société," "grand ouvrage publique," "travail commun," refleja su concepto antropomórfico del castor. En cierto sentido, dice, estos animales llegan a superar al hombre: "...ils jouissent de tous les biens que l'homme ne sait que desirer." (p. 294). 
poema descriptivo. Resulta obvio que a través de los castores el poeta está exponiendo de un modo indirecto su teoria de la comunidad ideal. Tomás Moro estableció la sociedad ideal en algún lugar de América con su Utopía en 1516; pero fue el ilustre primer obispo de Michoacán, don Vasco de Quiroga, quien, tomando su inspiración de la Utopía de Moro, fundó dos pueblos-hospitales, o comunidades de vida colectiva, en Sante Fe, cerca de la Ciudad de México, y en Michoacán. Hay razones muy sólidas para creer que don Vasco utilizó el ejemplar de la Utopía que pertenecía a Fray Juan de Zumárraga, el primer arzobispo de México, que echó los cimientos del humanismo mexicano en el siglo XVI. ${ }^{211}$

El plan que tuvo Fray Bartolomé de las Casas en 1517 de fundar una colonia agraria en Cumaná, Venezuela, que se llevó a la práctica en 1519, y más tarde, su famoso experimento en la Comunidad de Verapaz, Guatemala, colocan al fraile dominico dentro de la corriente de renacentistas utópicos. ${ }^{22}$ Notorio es también el establecimiento del comunismo jesuítico de los indios guaraníes en las misiones del Paraguay a principios del siglo XVII, al que Mariano Picón-Salas ha llamado "...la extraña utopía social de los jesuitas en los bosques del Paraguay.",

Siguiendo la fórmula clásica de la invocación a una deidad, Landívar se dirige a Diana, que personifica la luna, y que entre sus atributos cuenta el de ser diosa de la caza, procedimiento que en la Rusticatio Mexicana es puramente imitativo y ornamental. El propio poeta, seguramente en previsión de probables censuras, nos dice que no les reconoce a los dioses paganos poder ni divinidad alguna. "Alude Landívar a la "vasta América" cuando sitúa la zona de los castores al norte entre los 30 y 60 grados de latitud, procedimiento que refleja el carácter científico y enciclopédico del período. Presenta a los castores como poco

${ }^{21}$ Véase el escrito Información en Derecho, donde desarrolla don Vasco sus ideas sobre la sociedad ideal india, en Don Vasco de Quiroga. Documentos. Edic. de Rafael Aguayo Spencer (México, 1941), pp. 289-406. Según Silvio Zavala, Ideario de Vasco de Quiroga (México, 1941), p. 15, la Información en Derecho "...es la fuente más valiosa de cuantas conocemos para estudiar el ideario de Quiroga ante los delicados problemas que planteó la conquista y colonización de España en las Indias." Para la historia del experimento jesuita en el Paraguay, ver Clovis Lugon, La République des Guaranis, 1610-1768 (Paris, 1970), y François Sagot, Le communisme au Nouveau Monde (Paris, 1910).

22: Nous parlions plus haut de la précision utopique avec laquelle est exposé en 1517 le systeme d'association entre les 'libres' Indiens et les paysans espagnols." Marcel Bataillon, Etudes sur Bartolomé de Las Casas (Paris, 1966), p. 46. Para la historia de Cumaná, ver Manuel Giménez Fernández, Bartolomé de Las Casas (Sevilla, 1960), II, pp, 1103-1167. Para la de Vera Paz, ver Bataillon, op. cit., pp. 137-202.

${ }^{23}$ De la Conquista a la Independencia (México, 1950), p. 68.

${ }^{24}$ Guido Mancini Giancarlo, "La Rusticatio Mexicana de Rafael Landívar," Revista de Indias, núm. 39 (enero-marzo 1950), pp. 808-809, dice de las invocaciones: "Este recurso, bastante fastidioso y aburrido, es sólo una tentativa de quedar fiel a la antigüedad, pues toda la obra nada tiene de pagano." El padre Juan Andrés, al referirse al poema De partu Virginis (1526) de Iacopo Sannazaro, encontró extravagante y absurda la mezcla de entidades paganas y de la religión cristiana; "...a muchos les disgusta, no sin razón, aquella mezcla de Aqueronte, el Cerbero, los Angeles y Jesús; .... Origen, op. cit., III, p. 325. 
atractivos desde el punto de vista físico, pero de inteligencia sobresaliente y de nobles cualidades, de buena índole, muy pacíficos, ajenos a las pasiones de odio y venganza, libres de hondas preocupaciones $y$ amantes del trabajo. Impresionante y dramática es la referencia a la construcción de la "ciudad." Traza el cuadro de los árboles roídos por los incisivos de los castores, cayendo uno tras otro a través de un arroyo, mientras que los ciudadanos del bosque que los tronchan, aunque sorprendidos por los formidables ruidos, siguen impertérritos su tarea. Este pasaje nos recuerda la Eneida, cuando Virgilio describe la construcción de Cartago:

Instant ardentes Tyrii, pars ducere muros molirique arcem et manibus subvolvere saxa, pars optat locum tecto et concludere sulco. (I, 423-425)

(Parte de los tirios ardorosamente se apresuran a trazar los muros, a levantar la ciudadela y a empujar las piedras con sus manos, y otros escogen sitio para sus casas y trazan con un surco el correspondiente espacio.)

La imitación se revela comparando estos versos de Virgilio con los de Landívar:

Pars findunt teretes frondoso littore truncos, pars lentos caedit viridanti ex ilice ramos, et pars argillae cumulos humentis acervat. (91-93)

(Unos parten los troncos lisos en las riberas frondosas, otros desprenden las ramas obstinadas, y otros amontonan pilas de barro húmedo.)

Landívar logra un efecto dramático y sensorial, utilizando la anáfora y la aliteración de dentales y sibilantes, con el predominio de los pies rítmicos espondeos. Los castores construyen con la precisión de ingenieros, excavando, colocando estacas, atándolas con ramas y poniendo mezcla. Aunque trabajan colectivamente, cada uno tiene su especialidad, y cada uno conserva su individualismo escogiendo la forma de casa que más le acomoda. Tienen también un sentido de lo estético, que se manifiesta en el modo cómo preparan y embadurnan con barro las paredes de las casas, cómo lo hacen los yeseros, y luego adornan la casa artísticamente con ramos de follaje. En un símil hiperbólico dice el poeta que aunque las paredes de una casa estén adornadas con sedas, y los techos repujados de oro y plata, no se pueden comparar con las paredes de las casas de los castores, comparación que no nos parece una mera figura retórica, pues en toda su obra el poeta muestra desprecio por la riqueza material a la vez que una profunda admiración por la naturaleza.

Dos veces emplea la palabra "res publica" para significar la comunidad en que viven los castores, y hace notar que entre ellos existe la división del trabajo y un fuerte espíritu comunal. Los obreros rendidos por el esfuerzo físico son sustituidos por solícitos camaradas, y los jóvenes respetan y cuidan a los mayores, dejándoles los pisos bajos de las viviendas. Previniendo la escasez del invierno, los castores recogen durante el resto del año, y guardan en lugares 
señalados, una gran provisión de alimentos destinados para la comunidad. Landívar subraya su vida idílica, en la que sólo hay amor y reposo, sin riñas, ni venganzas, ni robos:

Nulla domos unquam discordia miscet, nulla movet pravas contentio turbida lites; nec foedis unquam spoliantur tecta rapinis, sed cives alma tranquilli pace fruuntur. (234-237)

(Ninguna discordia jamás invade sus umbrales, ninguna controversia les mueve a riñas viciosas; sus hogares nunca son saqueados por la infame rapiña; los ciudadanos gozan de amable paz y tranquilidad.)

Estos industriosos animales tienen también sus pasatiempos, algo muy necesario en la república ideal, y Landívar los describe con gracia y humorismo. Les encanta asomarse por las "amplias ventanas" (patulis...fenestris) para coger las "suaves brisas" (jucundas auras) y luego sumergirse en las "aguas heladas" (gelidas...undas). Así permanecen un largo rato para rehacer sus cuerpos agotados por el trabajo.

La llegada de la primavera es motivo de gran regocijo, y el poeta habla con mucha ternura del tiempo del celo y de los instintos maternales. El cuadro de los pequeñuelos jugueteando y corriendo tras sus madres es simpático y humano. La conducta del padre, sin embargo, es motivo de censura:

Tunca sociata nova genitrix suavissima prole sedula vernantes, legio ceu caetera, lucos advolat, et crustas truncorum pascitur udas. Impiger at genitor, simul ac vernantia flore prata novo rident, tectis se surripit altis, crudelisque domi sobolem cum matre relinquit. (261-268)

(Luego la tierna madre acompañada de sus hijos, junto con toda la comunidad, corre solícita al verde bosque a comer las jugosas cortezas de los árboles. Pero el padre enérgico, tan pronto como los prados se sonríen con nuevas flores, se escabulle de su casa espléndida, y cruelmente abandona a sus hijos.)

Aunque esta sociedad es "natural" y casi ideal, hay algunos individuos de conducta antisocial, como los ladrones. Para éstos el castigo es el exilio. La vida del exilado es penosa porque está forzado a errar por los bosques y campo abierto, exponiéndose al peligro de los cazadores. No puede edificar su casa a la orilla de un río, pues seguramente sería descubierto, y como consecuencia está condenado a habitar los agujeros que se encuentran por los márgenes de ríos y arroyos. Es una vida de desolación y dolor. Dice el poeta que estos expulsados "viven la vida del destierro entre negras sombras" (Et vitam degit nigris exterris in umbris, 283). Aquí y en otros lugares de la Rusticatio Landivar refleja la angustiada intimidad del exilado, sin esperanza de alivio en su penoso destierro. Relacionada con esta idea hay otra que el autor, apesadumbrado, expresa en el libro de los castores: la referente al inapreciable don de la libertad. Cargados de emoción están los versos que, sin duda, aluden a su vida de limitaciones en Bolonia. 
Ac nisi libertas pretioso tangat honore, nulla Fibrum poterit curae prosternere moles. (47-48)

(Ninguna masa de pesares puede romper el espíritu del castor, a no ser que afecte a aquella preciosa gloria que se llama libertad.)

Landívar es aquí, en efecto, el castor americano, sometido con sus compañeros de infortunio, en lo que le quede de vida, a la cárcel del destierro.

Desgraciadamente la paz idílica no perdura. El poeta enumera a los enemigos naturales del castor, como el lobo y el oso, pero el peor de todos es "violens homo," el hombre violento. La avaricia humana en busca de la piel del castor comenzó muy pronto en la historia de América, y ya en el siglo XVIII los cazadores iban acabando con estos pobres animales. ${ }^{25}$ Landívar introduce aquí, y en otras partes de la Rusticatio, el tema de la violencia y de la destrucción. En lo que viene a ser una epopeya heroicocómica en miniatura, con reminiscencias virgilianas, la comunidad entera de castores aparece ante la aproximación del cazador temerosa y excitada, y con las "orejas erguidas" (arrectis auribus). Uno de ellos, apercibido del peligro, lo advierte a los dèmás, azotando el agua con su ancha cola. Por todas partes hay confusión y caos, rompen a correr, y se salvan los que pueden. De bien poco sirve a los industriosos castores todo su ingenio contra la astucia y maldad de los seres humanos. Con vivo realismo y riqueza de detalle describe el poeta los métodos brutales y repugnantes que emplean los cazadores para coger a las desventuradas víctimas. Toda esta admirable república utópica termina miserablemente en tantas o cuantas docenas de pares de "elegantes botas" (caligulas subtiles).

¿A qué conclusiones podemos llegar sobre el Libro VI de la Rusticatio? El poeta, como corresponde a un ilustrado del XVIII, se documenta en las autoridades científicas de su tiempo en la materia, Buffon y Valmont de Bomare. Las descripciones de estos dos naturalistas sobre los castores tampoco vienen de la observación directa, o científica, sino de los relatos de los cazadores, indios y blancos, principalmente del Canadá. El cuadro que proyectan los dos, muy dieciochesco, al hablar de repúblicas, sensibilidad artística y exilio de los castores, aunque tenga alguna base de verdad resulta exageradamente antropomórfico y romantizado. Landívar, usando y abusando de los derechos del poeta, humaniza a los castores aun más al aseverar, por ejemplo, que los jóvenes cuidan a los viejos, y que los obreros alivian a sus compañeros agotados por el trabajo. Lo que tenemos aquí, por implicación, es el trazado visionario de una sociedad comunal idealista. Uno inevitablemente piensa en las clásicas utopias, como la República de Platón, la Utopia de Tomás Moro y el Commonwealth of Oceana de James Harrington. Nos parece entrever una gran semejanza entre la república de los castores y la Civitas solis, La ciudad del sol, de Tomás Cam-

25“"In 1763, the Hudson's Bay Company sold 54,670 Beaver skins at one sale." A. Anderson, $A$ General History of Quadrupeds (New York, 1804), p. 419. 
panella. ${ }^{26}$ En ésta, como en la Rusticatio, el amor al Estado sustituye al amor propio. Todo es paz y armonía. No existen celos, ni odios, ni venganzas. Las viviendas son comunales, hay distribución del trabajo, y los jóvenes atienden y respetan a los mayores. Y para los disconformes y los envidiosos que demuestran una conducta antisocial está el castigo del exilio. En lo que no coinciden Landívar y Campanella es en algo que pudiera parecerse a la recomendación que éste hace de la pena de muerte para toda mujer que use maquillaje. Es muy de notar también que esta representación del estado comunal, con su énfasis en la igualdad, paz, y libertad personal, pertenece a esa gran corriente de ideas relacionadas con las teorías de igualdad social, en organizaciones regidas por leyes y gobiernos adecuados, de pensadores como Rousseau, Voltaire, Montesquieu, Morelly y Mably.

Las fuentes literarias más directas del Libro VI de la Rusticatio parecen ser el XIV del citado Praedium Rusticum, ${ }^{27}$ donde su autor, Vaniere, habla de la organización social y política de las abejas, y la cuarta Geórgica, en que Virgilio pinta la vida de estos insectos, su organización social y su meta común. Las teorías políticas y sociales que expone Vanière en el Praedium son las que desarrollan y proponen los racionalistas del XVIII. En la sociedad colectiva de Vanière no existen los bienes privados ni la autoridad del Estado. En este sentido es algo similar a la anarquía. Cada abeja se dedica al trabajo que es más de su agrado, y en vez de avaricia y odio hay generosidad y amor. De varios ejemplos que se pudieran recordar, cito a continuación el sorprendente parecido que hay entre el uso de los bienes comunes de las abejas de Vanière y el de los castores de Landívar. Dice Vanière de las abejas:

privatae rei studio ne publica damnum res, ut in humana patiatur gente, reponit in commune cibos; venturae provida Brumae, quos Aestate legit: populum coalescit in unum quo neque justitiae, nec amantior ordinis alter. (Liber XIV, p. 258)

(Y para que la república no sufra el daño del deseo de riquezas privadas, como ocurre entre los hombres, y teniendo en cuenta el invierno que se

${ }^{26}$ Civitas Solis: Idea reipublicae philosophicae (Francfurti, 1623). Para Esteban Arteaga, ex jesuita español, contemporáneo de Landívar y autor del famoso tratado de estética, La belleza ideal, Campanella es uno de los que ocupan "...inútilmente tanto lugar en la historia de la filosofía, y son, a mi ver, más bien soñadores que filósofos." Carta de Arteaga a Saverio Bettinelli, 29 de enero de 1786, en Batllori, op. cit., p. 170.

${ }^{27}$ El Praedium Rusticum, de Jacques Vanière, 1664-1739, el "Virgilio francés," refleja la pasión del XVIII por el poema didáctico del campo. La primera versión del Praedium salió en París en 1707, y la versión completa de los dieciséis libros, en 1746. Al comienzo de las dos ediciones de la Rusticatio, Landívar cita estos dos versos del Libro Primero (versos 21-22):

Secreti tacita capior dulcedine ruris: quod spectare juvat, placuit deducere versu.

(Me encanta la muda dulzura del escondido campo; me deleita contemplarlo, y me ha ser-

vido de placer describirlo en verso.)

Nuestras referencias al Praedium son por la edición de París, 1756. 
acerca, la abeja coloca el alimento que se recoge en verano, en un almacén colectivo. El pueblo se funde en uno, y nadie ama la justicia y orden más que ellas.)

En el Libro VI de la Rusticatio nos encontramos con similar conducta de los castores:

Ut vero finem tectis posuere superbis, privatae studio vitae nudata caterva tota sodalitio rursus se prompta resignat. Praenoscit luces, mensesque experta futuros, horrida queis campos devastat frigore bruma,

Turba dein complet dapibus de robore sectis horrea vasta domus socio fabricata labore, ordineque arboreas epulas insomnis acervat, aptius ut socii lucorum frusta resumant. (195-199); (214-217)

(Y cuando han terminado sus elegantes casas, los castores, habiendo perdido su deseo de una vida privada, se acomodan pronto otra vez a la vida colectiva. Por experiencia perciben la llegada de los días y meses en que el invierno feroz deschace los campos con su hielo.... Entonces llenan de ramas y cortezas el gran almacén construido como empresa colectiva, y sacrificando el sueño, amontonan ordenadamente el alimento, para que sus camaradas tengan acceso fácil a estos trozos del follaje reservado.)

Al final de su discusión sobre las costumbres de las abejas, Vanière alaba la famosa comunidad de indios guaraníes que los jesuitas españoles habían fundado en las misiones del Paraguay. Los jesuitas reunieron miles de familias indias en poblados que se llamaron reducciones y que recuerdan los pueblos-hospitales de Vasco de Quiroga, y hacia fines del siglo XVIII las treinta o más reducciones organizadas tenían una población de unos cien mil individuos. En esta gran comunidad distribuida en núcleos colectivos, con asignación de tierras de cultivo a cada familia, han querido ver muchos europeos la realización de una verdadera utopía. Vanière describe la comunidad de sus abejas como una república de colmenar, y es muy verosímil que Landívar tuviera esto en cuenta al concebir la república de sus castores, aunque nunca alude directamente a ninguna obra que expusiera ideas utópicas.

Podemos agregar que en el libro XIII del Praedium Vanière habla de la cría de palomas, y hay varios pasajes que bien podrían haber sido la inspiración para algunas de las descripciones del Libro VI de la Rusticatio. Notamos, por ejemplo, una gran semejanza entre los versos del Praedium que siguen a continuación y los versos 234-37 del poema de Landívar, citados arriba:

Omnibus una domus, quae sola impervia rixis permanet, unus inest amor omnibus, una voluntas; et quae saepe fere populos Discordia motu exagitat, nunquam civilibus otia bellis turbavit Cypriae volucris;...

(Praedium, Liber XIII, p. 248)

(Hay una morada para todos, que permanece inaccesible a toda disen- 
sión; hay un solo amor, una sola voluntad; y la Discordia, que a menudo agita con perturbaciones a los pueblos, nunca ha podido turbar con guerras civiles la plácida vida del ave de Venus.)

En resumen, la utopía de Landivar es la de una sociedad cristiana comunal, no precisamente definida, pero claramente relacionada con las utopías tradicionales, sobre todo con la de Campanella y con las teorías político-sociales divulgadas en el siglo XVIII. La inspiración literaria en gran parte viene de Vanière y de Virgilio, mientras que ciertas escenas drámaticas son de inspiración exclusivamente virgiliana. Aparte de la idea utópica concreta del Libro VI, este poema, en su conjunto, con la revelación de las bellezas naturales de México, y Guatemala, de la abundancia de animales y plantas, de la fertilidad de la campiña, de la riqueza de las industrias, y de la alegría de las diversiones, parece querer dar la impresión de que América es una especie de paraíso utópico. Clavijero, en su Historia antigua de México, que es una refutación de los denigradores de América, al describir el clima, la tierra, las plantas, las aves, etcétera, pinta también una Nueva España paradisíaca. Y el padre Alegre, en su Historia de la Compañia de Jesús, no puede contener su entusiasmo por América al decir: "...parece que la naturaleza ha hecho en las demás partes un ligero ensayo de lo que quería perfeccionar en la América, y singularmente en la Nueva España, que es como el centro de toda ella."28

Desde que Menéndez y Pelayo, en 1893, calificó a la Rusticatio Mexicana como "una total pintura de la naturaleza y de la vida del campo en la América Septentrional," obra de "color local americano que otros han buscado sin for,tuna," ${ }^{29}$ muchos historiadores de la literatura han repetido esta idea, insistiendo, respecto al poeta guatemalteco, en la fidelidad de sus observaciones de naturalista, en su realismo didáctico, y en su gran valor como criollo que, por razones no fácilmente comprensibles para ellos, prefirió escribir en latín.

Alfonso Reyes vio la ventaja nacional que se podía derivar de Virgilio y de Landívar cuando sugirió la lectura de las Geórgicas y de la Rusticatio como remedio parcial al problema agrario de México. "Y nada tendría de extraño-dice-que, como otro acto más de la adhesión mexicana a los fastos de Virgilio, se recomendara en las escuelas agrícolas - y de modo general en las escuelas primarias - la lectura de la Geórgicas para despertar en la mente de los niños la vocación del campo, vocación que hoy casi se confunde con la vocación de la patria.... Y la lectura se acompañaría con fragmentos de nuestras Geórgicas, o sea, la Rusticatio Mexicana de Landivar (traducción en prosa por Loureda y en verso por Escobedo), para hacer sentir así, de un modo palpable, cómo el espíritu clásico puede acercársenos y hasta tener utilidad nacional."

Luis Cardoza y Aragón tuvo la originalidad de decir, al comentar la

${ }^{28}$ Historia de la Provincia de la Compañia de Jesús de Nueva España. Edic. de E. J. Burrus y F. Zubillaga (Roma, 1956), I, 29.

${ }^{2}$ Antología de poetas hispano-americanos (Madrid, 1893), I, pp. clxviii-clxix.

30 “Discurso por Virgilio," en Obras Completas (México, 1956), XI, pp. 166-167. 
Rusticatio, que no sería él quien repitiese una vez más la opinión de don Marcelino Menéndez y Pelayo. ${ }^{31}$ Este crítico guatemalteco señaló acertadamente que la $R$ usticatio es un tipo de poema que, aunque agradaba al lector refinado y culto del siglo XVIII, producía cansancio al lector contemporáneo. Confiesa que le gustaba el poema, pero que sólo podía leerlo en partes y a ratos. Alaba los "relámpagos poéticos" de Landívar, y da muestras de su facilidad de percepción cuando dice: "Landívar es diáfano, es limpio a lo largo de su ejercicio lírico, y hasta la prolongada diafanidad nos cansa.",

Sin embargo, John B. Trend, distinguido hispanista inglés, no se siente tan aislado como Cardoza y Aragón cuando éste dice del poema, comparándolo con un cuadro religioso o con un ídolo precortesiano, que casi no lo entiende. Para Trend, el poema es mucho más vital y vibra con la emoción del poeta, especialmente cuando expresa su nostalgia por América y lamenta el exilio. Tal sentimiento es universal y eterno, y Trend lógicamente recuerda a los exilados españoles de nuestros días:

It [la Rusticatio] has the pathos - the stab which can add something to a bare description and convert it into poetry; the quality which we find, for instance, in Unamuno wandering in Paris like a lost soul among the criss-cross of boulevards, avenues, squares and 'sewer-like' entrances to the Métro, but dreaming all the time of the Sierra de Gredos. The Spanish exiles in Bologna at the end of the eighteenth century were a select band, something like the Spanish 'Institutionist' exiles of today in Mexico: select, and conscious that they were the bearers of a fine tradition and a civilized outlook which they spread while they were gradually absorbed into the life of their new country. ${ }^{33}$

$Y$ más recientemente, Graciela $P$. Nemes conceptúa a Landívar como un intelectual, producto de la Ilustración, y califica la Rusticatio como "...a document of historical significance revealing the conscious attempt of a colonial Spanish American intellectual to incorporate himself into the new currents of thought at a time when colonial tradition still weighed heavily on him.",

Aunque no se puede negar el carácter descriptivo del poema, no debe ignorarse otro aspecto importante en pro de sus merecimientos: la reacción humana del poeta ante los cuadros de la naturaleza que contempla. Como las Geórgicas de Virgilio no son un manual de labranza, a pesar de que el poeta dé consejos a los cultivadores de la tierra, porque su descripción encierra riqueza de alusiones y profunda filosofía, así la Rusticatio no es meramente descriptivo-

31 Apolo y Coatlicué (México, 1946), p. 87.

32 Ibid, p. 89 .

33."Rusticatio Mexicana," en Estudios Hispanicos. Homenaje a Archer M. Huntington (Wellesley, Mass., 1952), p. 605.

34“'Rafael Landívar," art. cit., p. 301. 
didáctica; es también una sutil revelación del mundo de ideas de su tiempo reelaboradas en la mente del poeta. La leyenda del rey indio tirano de Atzcapotzalco,que aparece en el libro sobre los jardines flotantes, por ejemplo, es una alusión a la tiranía universal. En el libro sobre la erupción del volcán Jorullo, en Michoacán, que comenzó en 1759, Landívar reflexiona sobre lo precario de las cosas humanas; y recordándonos al padre Feijoo, cuyas ideas circulaban en América, condena vigorosamente la superstición popular. $\mathrm{Y}$ a estos ejemplos se podrían añadir muchos otros que revelan la capacidad de Landívar como pensador del período de la Ilustración.

El Libro VI, uno de los más originales de la Rusticatio Mexicana, es buen ejemplo de un bello cuadro de la naturaleza de América convertido en drama por la humanización de animales, por sus escenas de creciente tensión, por sus elementos heroicocómicos, por sus alusiones e imágenes clásicas, por sus toques de humorismo, por la compasión humana que rezuma, y por cierto sentido trágico de la vida de hombres y castores. Es uno de los cantos del poema que se lee con más agrado e interés, en el que revela la percepción del naturalista, la teoría social del racionalista ilustrado e idealista, y el espíritu o sentido humanitario. Este virtualmente olvidado Libro de los Castores, producto de la Ilustración europea, es una pequeña joya de la literatura criolla del XVIII, mostrada al público en vísperas de la proclamación de la independencia de las naciones hispanoamericanas. Rafael Landívar, en conclusión, ocupa, por relevantes merecimientos, puesto de honor entre los precursores ilustrados de la independencia americana. Termina el poema con una exhortación a la juventud de América, que da buena idea de su mentalidad de innovador:

Disce tuas magni felices pendere terras, divitiasque agri, praestantia munera coeli, explorare animo, ac longum indagare tuendo. Alter inauratos Phoebo lumine campos incautis oculis, brutorum more, sequatur, omniaque ignavus consumat tempora ludis. Tu tamen interea, magnum cui mentis acumen, antiquos exuta, novos nunc indue sensus, et reserare sagax naturae arcana professa ingenii totas vestigans exere vires, thesaurosque tuos grato recludere labore.

(Appendix, 102-12)

(Aprended a estimar vuestras tierras fecundas, a explorar con entusiasmo y a investigar con cuidado las riquezas del agro y los dones espléndidos del cielo. Que vayan otros por los campos dorados por Apolo, con los ojos distraidos a la manera de los brutos, y que desperdicien su tiempo en los juegos. Pero vosotros mientras tanto, vosotros, que tenéis una inteligencia aguda, deshaceos de ideas envejecidas, aprovechar los nuevos descubrimientos, entregad toda la fuerza de vuestras mentes a la búsqueda de ignorados bienes, y con trabajo gustoso descubrid vuestros tesoros.) 
